\title{
Bizans Resim Sanatında Öteki Kadın Tasviri: Hacer
}

\author{
Hatice DEMIR ${ }^{1}$
}

\begin{abstract}
$\ddot{O} \mathbf{z}$
$\mathrm{Bu}$ çalışmanın konusunu Bizans resim sanatında Hacer'in tasviri oluşturmaktadır. Eski Ahit Yaratılış episodu 16: 1-16 ve 21: 8-21'de Hacer ile ilgili referanslar bulunur. Yaratılıs 16: 1-16'ya göre; İbrahim'in eşi Sarah/Saray/Sare'nin, Hacer isminde Mısırlı bir cariyesi/hizmetçisi vardır. Sarah ileri yaşına gelmiştir ve kısırdır. Hacer ve İbrahim'in birlikte olmasına müsaade eder ve Hacer, İsmail'e hamile kalır. Hacer, Sarah'ı küçümser ve bunun üzerine Sarah, Hacer'i İbrahim'e şikâyet eder. Hacer kaçar ve bir pınar başında Cebrail ile konuşur. Hacer ile ilgili olarak diğer bir referans Eski Ahit Yaratılış episodu 21: 8-21'de geçer. Sarah geç yaşında hamile kalır ve İshak doğar. Sarah, İbrahim'den Hacer’i kovmasını ister. Hacer "öteki kadın" figürüdür. Soylu değildir ve hanımı tarafından horlanır. Gerek oğlu İsmail ve gerekse kendisi ikinci sınıf insandır. Görmüş olduğu baskı üzerine kaçmayı dener. Tanrı'nın meleği geri dönmesini ve hanımına itaat etmesini söyler.

Hacer'in, Kitab-1 Mukaddes'te çizmiş olduğu "öteki kadın” figürü, Bizans resim sanatına da yansır. Örneğin, Sarah ile kıyaslandığında, yapılan tasviri yok denecek kadar azdır. Tasvirler kilise resim programlarında, genelde İbrahim'in Hayat siklusu içerisinde yer alır. San Marco katedralinde yer alan İbrahim siklusu içerisinde Hacer' in iki ayrı tasviri ile karşılaşılır. Bunun dışında kitap resmi örneklerinde de Hacer'in tasvirleri vardır.
\end{abstract}

Anahtar kelimeler: Hacer, Eski Ahit, Öteki Kadın.

\section{The Depiction of the Other Woman in Byzantine Painting: Hagar}

\begin{abstract}
The subject of this study is the depiction of Hagar in Byzantine painting. There are some references of Hagar in Old Testament in Genesis Episode 16: 1-16 and in 21: 8-21. According to Genesis 16: 1-16; Abraham's wife Sarah had an Egyptian concubine/maid named Hagar. Sarah was old and infertile. She allowed Abraham to have sexual intercourse with Hagar. Hagar became pregnant to Ismail. After her pregnancy, Hagar began to scorn her lady Sarah. Sarah then complained of Hagar to Abraham. Hagar escaped and talked to angel next to a spring. Another reference to Hagar was in Genesis 21: 8-21. According to synoptic; Sarah became pregnant to Isaac at her old age and Isaac was born.

According to the references mentioned above, Hagar is the "other woman" figure of Old Testament's Genesis episode. The figure of "other woman" in Bible drawn by Hagar was also depicted in Byzantine painting. If we compare her depiction with Sarah in Byzantine painting, hers were rather rare. Her depiction usually took place in the depiction of Abraham's cycle if it was a part of a painting program of a church.
\end{abstract}

Keywords: Hagar, Old Testament, other woman.

Received/Geliş: 27.02.2020

Accepted/Kabul: 22.05.2020

$\mathrm{Bu}$ araştırma makalesi Etik Kurul Onayı gerektirmemektedir.

${ }^{1}$ Dr. Öğretim Görevlisi, Kastamonu Üniversitesi, Sosyal Bilimler Enstitüsü, hdemir@kastamonu.edu.tr, $10 / 0000$ 0002-5801-5841

(Makale türü: Araştırma makalesi) 


\section{Giriș}

Bu çalışmada Bizans resim sanatında Eski Ahit kaynaklı Hacer tasvirleri ele alınmıştır. Sami kökenli iki ulus; İsrailoğulları ve Araplar İbrahim'in iki oğlu İshak ve İsmail ile birlikte devam etmiştir. Bu iki oğuldan İshak, İbrahim'in eşi Sarah'dan, İsmail ise Mısır kökenli köle Hacer'den olmadır ${ }^{1}$. İbrahim ve karısı Sarah ilerleyen yaşlarına rağmen çocuk sahibi olamamışlardır. Hacer, Sarah'ın Mısırlı cariyesidir. Sarah'ın izni ile İbrahim ve Hacer birlikte olmuş ve İsmail doğmuştur. Gerek Hacer ve gerekse Hacer'den olma İsmail hem Sarah hem de Sarah'ın oğlu İshak ile dalga geçtikleri gerekçesi ile kovulmuşlardır.

Bu özellikleri ile Hacer, Bizans resim sanatında “öteki kadın” imgesi olarak karşımıza çıkar.

\section{Eski Mezopotamya ve İbrani Geleneklerine Göre Kadının Aile İçerisindeki Yeri}

İbrani toplumunda ailede söz sahibi olan isim babadır ${ }^{2}$ ve bu yönüyle İsrail toplumu ataerkil $^{3}$ bir toplum geleneğinden gelir (Faleni, 2008, s. 66).

Eski İbrani toplumunda tek eşlilik öncelenir ancak erkek çocuk sahibi olmak soyun devamı için çok önemli olduğu için, kadın eşin kısır olması durumunda ${ }^{4}$, çocuk sahibi olmak için cariye/odalık ${ }^{5}$ kavramı ile de karşılaşılır (Faleni, 2008, s. 67).

Eski Mezopotamya kültüründe; ailenin varlığı, çocuk sahibi olmanın önemi, evli kadın eş, köle cariye ve cariyeden olma çocukların aile içerisindeki durumuna dair bilgilerin kökeninde, eski Sümer ve Asur gelenekleri vardır. Lipith-Ishtar ve Hammurabi kanunlarında yer alan kadın, cariye ve çocukların statüsü ile ilgili kavramlar ile Eski Ahit’te yer alan Hacer ile Sarah ve her ikisinden olma çocukların hakları ile bağlantılı referanslar arasında benzer özellikler olduğu gözlemlenir.

Bu benzer özellikleri kısaca değerlendirecek olursak; Kitab-1 Mukaddes’te Hacer ve oğlu İsmail ile ilgili en önemli referanslar, Yaratılış episodu 16:1-15'te geçer. Bu bağlamda, Yaratılış 16'daki bilgiler ile Lipith-Ishtar ve Hammurabi kanunlarında bahsi geçen; aile, cariye, eş, çocuk sahibi olmak ile ilgili bilgiler benzer özellikler gösterir. 16:1'de İbrahim'in karısının adı Sarah olarak verilir. Buradan da anlaşılacağı üzere İsrailoğullarında aile kavramı gelişmiştir. Aynı

\footnotetext{
${ }^{1}$ Eski Ahit Yaratılış episodu 25:1-3’te; İbrahim'in ileriki yaşlarında Keturah/Kantura isminde bir kadınla daha olan evliliğinden bahsedilir. Bu kadından olma çocukları da başka ulusların atasını oluşturmuştur.

${ }^{2}$ Ailede baba, çocuklarını köle olarak satabilme hakkına sahiptir. Ancak çocukların yaşam hakları konusunda söz sahibi olması konusunda özgürlüğü yoktur (Faleni, 2008, s. 66).

${ }^{3}$ Eski Ahit'te; Sarah, Hacer, Rebekah, Leah ve Rakel ataerkil bir toplumda erkek evlat doğuran kadın figürleri olarak karşımıza çıkar (Hawk, 2011, s. 9).

${ }^{4}$ Eski İbrani geleneklerine göre, çocuk sahibi olamayan kadın eksik kabul edilir (Grimes, 2004, s. 5).

${ }^{5}$ Pentateuk'daki referanslara göre, belirli bir süre zarfında birine hizmet etmek için birinin himayesine girilebilir ancak kalıcı kölelik Yahudi soyundan olmayanlar için geçerlidir (Faleni, 2008, s. 75).
} 
bölümde Mısırlı Hacer'in, Sarah'ın cariyesi olmasından bahsedilir. 16:2'de Sarah çocuk sahibi olamamasından dolayı üzüntüsünü dile getirir. Bunun Tanrı'nın bir cezalandırması olduğu kanaatindedir. Buraya kadar anlaşılacağı üzere, İbrani toplumunda çocuk sahibi olmak elzemdir. Tek eşlilik öncelenmekte ama kadın eş çocuk veremiyor ise, cariyeden bir çocuk sahibi olunabileceği yargısına varırız.

Buna benzer ifadeleri gerek M.Ö. 1868 tarihli Lipith-Ishtar ve gerekse Hammurabi kanunlarında da görmek mümkündür. Buradan da anlaşılacağı üzere; İsrailoğulları, kendinden önceki Sümer ve Asur kanun geleneklerini devam ettirmiştir.

Lipith-Ishtar'da yer alan şu kanun maddesi yukarıdaki görüşümüzü destekler. "Eğger bir adamın karısı ona çocuk doğuramamış, ancak sokak meydanından getirtilen bir fahişeden çocuk sahibi olunmuş ise, doğan çocuklar babanın varisi olacaktır ancak fahişe kadının, evin kadını ile birlikte aynı evde yaşama hakkı yoktur.” (Roth, 1995, s. 1). Yaratılış 21:9-21'deki şu ifade; “...Ne var ki Sarah, Musırlı Hacer'in İbrahim'den olma oğlu İsmail' in alay ettiğini görünce, İbrahim'e "Bu cariyeyle oğlunu kov" dedi, "Bu cariyenin oğlu, İshak'ın mirasina ortak olmasın..." Sarah'ın Eski Ahit'te söylediği “onları kov, oğlum İshak'ın mirasına ortak olmasın” ifadesi yukarıda bahsi geçen Lipith-Ishtar maddesi ile benzerlik gösterir. Çünkü Sümer ve Asur geleneğinin bir devamı olarak, köle Hacer' in çocuğu mirasa ortak olabilmektedir. Ancak bir başka Lipith-Ishtar maddesi şu şekildedir; "Eğer bir adam evli ise ve karısı ona çocuklar doğurmuş ve çocuklar yaşıyor ise ve aynı adamın cariyelerinden de çocukları olmuş ise ve sahibi adam onlara özgürlügünü vermiş ise köleden olma çocuklar önceki çocukların mallarına ortak olamazlar." Bu kanun maddesinin de yine Sarah ve Hacer'in ve çocuklarının durumunu belirleme noktasında önemli bir etkisi vardır. Sarah başlangıçta çocuk sahibi olamamıştır. Ancak geçkin yaşında İshak’1 doğurmuştur. Böylece, cariyeden olma İsmail'in artık aynı evde mirasçı olarak kalmaması gerekmektedir.

Asur dönemine ait Hammurabi yasaları da bir erkeğin kadın eş ve hizmetçi/cariye ile olan ilişkisine açıklamalar getirir (Gürgen, 2018, s. 344). 144. maddede, "bir kadın kocasına bir köle vermiş ve ondan çocukları olmuş ise, koca ikinci bir eşi alamaz." 145. maddede "eğer kadın eşin çocuğu olmaz ise ve erkek eş ikinci bir eş almak isterse, eve gelen ikinci eş, ilk kadın ile eşit haklara sahip olamaz 6 ." 146. maddede, "eğer eş kocasına çocuk doğurması için hizmetçisini verir ve hizmetçi eşi ile eşit haklara sahip olduğunu iddia ederse, onu para ile satamaz ancak evinde hizmetçi olarak tutmak zorundadır." (Pinker, 2009, s. 6-7; https://avalon.law.yale.edu/ancient/hamframe.asp).

${ }^{6}$ Hacer' in, İbrahim'in çocuğunu doğurduğu için onun karısı olma iddiasını taşıyor olma ihtimali de yüksektir (Angel, 2013, s. 212). 
Yukarıda da belirtildiği üzere, gerek Lipith-Ishtar ve gerekse Hammurabi kanunlarının, Eski Ahit Yaratılış episodunda yer alan Hacer-Sarah ve İsmail-İshak'ın sosyal ve yasal statüleri üzerinde önemli yeri ve etkisi vardır.

\section{Kitab-ı Mukaddes'te Hacer ile İlgili Referanslar}

Eski Ahit’te Hacer ile bölümler şu şekildedir.

Hacer ve oğlu İsmail ile ilgili olarak Kitab-1 Mukaddes’te ilk referanslar Yaratılış 16 (Hacer ile İsmail) ve 21:8-21'deki (Hacer'le İsmail Uzaklaştırılıyor) episodlarında geçer.

Yaratılış 16'nın sinoptiği kısaca şu şekildedir; Hacer hamile kalması üzerine, hanımı Sarah'1 küçük görmeye başlar ve bunun üzerine Sarah, Hacer'e kötü muamelede bulunur. Bunun üzerine Hacer çöle kaçar. Çölde Rab'bin meleği ile aralarında bir sohbet geçer. Melek, ondan hanımına geri dönmesini ister. Melek ayrıca Hacer'e, hamile olduğu oğlunun adının 'Tanrı $d u y d u^{77}$ anlamına gelen İsmail ve bu çocuğun soyunun çok kalabalık olacağı vaadinde bulunur.

Daha sonra Hacer ve oğlu karşımıza Yaratılış 21:8-21'de çıkar. Episodun sinoptiği şu şekildedir. Sarah'dan olma İshak sütten kesilir ve büyük bir şölen verilir. İsmail, İshak ile dalga geçer ve bunun üzerine Sarah, Hacer ve oğlunun kovulmasını ister. İbrahim üzülerek Hacer ve oğlunu kovar. Hacer, çölde susuz kalır. Tanrı ona oğlunun kalabalık bir soyu olacağı sözünü verir. Çocuk büyürken Tanrı onunla kalır. Çocuk Paran Çölünde iyi bir okçu olur ve Mısırlı bir kadın ile evlenir.

Kitab-1 Mukaddes'te Hacer ile ilgili bir sonraki referans, 1. Tarihler 5:18-22'de Gad soyundan bahsederken "Hacerliler" ifadesi ile tanımlanır. Hacerliler ile mücadele eden Gad soyu, Tanrının yardımı ile Hacerlileri yenmiştir. Episodda; Gad soyunun sürgün döneminde yine Hacerlilerin topraklarında yaşadıklarına da değinilir.

Yeni Ahit'te Hacer ve dolaylı olarak oğlu İsmail ile ilgili referanslar, Galatyalılar 4:2131 “Sara'yla Hacer Örneği” episodu ile verilir. Pavlus; Galatyalılar'a seslenirken, İbrahim'in köle ve özgür kadından olan iki oğluna vurgu yapar. Kutsal Yasa altında yaşamak isteyenlere seslenir. Köle kadından olma oğul doğal yollardan olurken, Sarah'dan olma oğul Tanrı'nın vaadi ile gerçekleşmiştir. İki kadın, iki ayrı antlaşmayı simgeler. Sina Dağı'nı temsil eden Hacer köle bir çocuk doğurmuştur buna karşıllk göksel Yeruşalimi temsil eden Sarah ve oğlu özgürdür ve Pavlus, Galatyalılar’a özgür kadının oğlunu takip etmeyi önerir/öğütler.

\section{Hacer İsminin Kökenleri ve Hacer’in Kimliği}

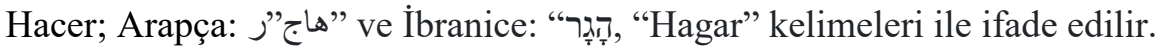

Hacer isminin kökeni Safaitik, Nabati ve Palmira kültürüne kadar uzanır ama en çok Eski Arap kültürü ile özdeşleşir. Arapçada "Hajara" "göç/hicret etmek" anlamında da kullanılırken,

\footnotetext{
${ }^{7}$ Geniş bilgi için bkz. Okoye, 2007, s.168-169.

${ }^{8}$ Arapça bir erkek ismi olan "Higir"'in, Nabati kökenli bir kadın ismi olma olasıllğı yüksektir.
} 
Sebe ve Etiyopya dilinde "kasaba" ve "şehir" anlamında da kullanıldığı durumlar vardır. Diğer taraftan, Hacer'in olumlu anlamları da mevcuttur. "Muhteşem" ve "besleyici" gibi sıfatlar bunlardan en önemlileridir ${ }^{9}$ (Drey, 2002, s. 181-182).

M.Ö. 2000'de Bahreyn'de Rimum sarayına ait bir çivi yazısı tablet ile I. Darius (521486) zamanına tarihlenen bir Pers şehri Susa'da bulunan bir Mısır hiyeroglif yazısında " $H g r w "$ ya da "Hacer" farklı telaffuzlar ile muhtemelen bir şehri ya da topluluğu ifade etmek için kullanılmıştır. İsim, Doğu Arabistan'da Bedevi Araplar ile ilişkilendirilmektedir. Orta çağa yaklaştıkça Müslüman ve Hıristiyan yazarlar Hacer ifadesini Doğu Arabistan coğrafyasını tanımlamak için kullanmaya devam etmişlerdir (Drey, 2002, s. 182).

Hacer, Tevrat kökenli söylentilere göre "insanı mülk edinmek" anlamına gelen "šifhah" kelimesi ile ifade edilmiştir. Ayrıca Hacer, Yaratılış 16:1'de “ $\breve{b}$ buddah" kelimesi ile de tanımlanır. "Ăbuddah"; kadın hizmetkar ve hizmetçi anlamında kullanılır. Ancak Hacer'in, episodun ilerleyen bölümünde 1ssızlıktan/çölden döndükten sonra " $a m a h$ " olarak ifade edildiği dikkat çeker (Drey, 2002, s. 183-184; Teubal, 1997, s. 49-50). Hacer'in Ugarit dilinde, " ̌s-f-h" "birlikte olmak" anlamına geldiği de bilinmektedir. Bu bağlamda Hacer'in, Avimelek tarafından Sarah ve İbrahim'e verilen ve onlarla birlikte gönderilmeye bir atıf niteliğinde "birlikte olmak" anlamına gelen "šifhah" kelimesi ile tanımlanması olasılığı yüksektir (Drey, 2002, s. 184; Spitzer, 1998, s. 9).

Hacer'in kimliği ve statüsü ile ilgili bilgiler ise şu şekildedir. Eski Ahit'ten edinilen bilgilere göre Mısır kökenli bir köle ya da cariyedir. İbrahim ve Sarah'ın Mısır'dan dönüşü esnasında, Yaratılış 20:14'te de belirtildiği üzere, Avimelek ${ }^{10}$ tarafından Sarah'a cariye olarak verilmiştir ${ }^{11}$. Arapların atası İsmail'in annesidir.

Hacer'in kişilik özellikleri ile ilgili olarak Eski Ahit kaynaklı göndermelerden şu bilgileri öğreniriz. Kibirlidir ama Tanrıya karşı gelmeyen bir yaklaşımı vardır. Eski Ahit’te yer alan Hacer ile melek arasındaki konuşmada, meleğin Hacer'e söylemiş olduğu; "hanımının yanına dön ve ona boyun ĕg" ifadesi de Kitab-1 Mukaddes'te ilk olması adına da önemlidir ${ }^{12}$.

\section{Hacer'in Öteki Kadın Olarak Kimliği}

Eski Ahit’te Hacer'in çizmiş olduğu kadın figürü, Sarah üzerinden değerlendirilerek karşılaştırmalı ele alınmalıdır. Sarah; soylu ve birinci kadın olma kimliği çizerken, Hacer; Mısır

\footnotetext{
${ }^{9}$ Hacer isminin etimolojik kökenleri ile ilgili olarak başka önermeler de mevcuttur. Geniş bilgi için bkz. (Adamo \& Erivwierho, 2005, s. 455-471).

${ }^{10}$ Hacer; İslam tefsirlerine göre, Mısır firavunlarından Senan bin Ulvan'ın, İbrahim'in karısı Sarah'a hediye ettiği Etiyopyalı bir köledir. (Https://www.turkcebilgi.com/hacer).

${ }^{11}$ Ayrica Tevrat kökenli efsanelere göre de Hacer Firavun soyundan gelmektedir (Drey, 2002, s. 183; Ginzberg, 1998, s. 108).

${ }^{12}$ Geniş bilgi için bkz. Kitab-1 Mukaddes Yaratılış 16: 9.
} 
kökenli ikinci kadın olma rolündedir. Bu bağlamda, Hacer’i öteki yapan ilk özelliği, farklı bir etnik kökenden geliyor olmasıdır.

Eski Ahit’te Hacer'i öteki kadın yapan diğer bir çıkış noktası, sosyal sınıf üzerinden ele alınır. Yaratılış 20:14'te de belirtildiği gibi, İbrahim ve eşi Sarah Mısır'dan dönerken, Avimelek'in onlara vermiş olduğu hediyeler arasında cariyeler de vardır. Bunlardan birinin Hacer olduğu görüşü hakimdir. Bu bağlamda, Hacer soylu bir kadın olan Sarah'a verilmiş bir köledir. $\mathrm{Bu}$ bağlamda aralarında bir sınıf farkı mevcuttur.

Yukarıda bahsi geçtiği gibi, Hacer'in farklı ve öteki yapan bütün nedenlerin arasında farklı bir etnik kökene ait olması başat rol oynar. Bu nedenle oğlu İsmail ve kendisi, İshak'a vaad edilenlere ortak olamaması için uzaklaştırılmışlardır.

Araştırmacı Gaiser (2014, s. 275); Eski Ahit referanslı biçimlenen Hacer kimliğini, modern insanın belleğinde algılanması noktasında görüş bildirir. Modern insanın zihninde Hacer, rızası alınmadan hediye verilen, daha sonra yine rızası olmadan cinsel ilişkiye zorlanan, hakları ihlal edilmiş bir kadın figürüdür. Hatta Gaiser bir adım daha ileri giderek bunun modern bellekte bir tecavüz olarak algılanma olasılığının yüksek olduğuna değinir.

Yeni Ahit Galatyalılar 4:25-26'da Pavlus, Galatyalılara seslenirken Sarah'1 ve oğlu İshak'1 övgü dolu ifadeler ile onure etmektedir. Sarah ve İshak'a yapılan övgü dolu ifadeler ise öteki kadın figürü Hacer ve oğlu İsmail üzerinden pekiştirilmektedir.

\section{Bizans Resim Sanatında Hacer Tasvirleri}

Bizans resim sanatında Hacer temalı tasvirler yok denecek kadar azdır. Eski Ahit kaynaklı tasvirlerde Sarah ile kıyaslandığında, Hacer daha ziyade öteki kadın tasviri olarak yerini almaktadır ve nicel olarak değerlendirildiğinde, Sarah tasvirleri, Hacer tasvirlerinden sayıca daha çoktur.

Sarah, en çok İbrahim 'in Misafirperverliği sahnesinde karşımıza çıkar ${ }^{13}$. İbrahim'in, kendilerini ziyarete gelen üç meleği ağırladığı sahnede yer alan Sarah, bazen İbrahim ile birlikte meleklere hizmet ederken, bazen de bir perde/kapı arkasından üç meleği ve İbrahim'i izlerken tasvir edilmiştir (Resim 1). İkonografik olarak ele alındığında, perde arkasından izleme olayının bir anlamı vardır. Üç melek bu ziyaretlerinde, Sarah ve İbrahim'e geçkin yaşlarına rağmen İshak’1 müjdelemektedirler. Perde/kapı imgesi burada Sarah'ın, Tanrı'nın müjdeli haberine karşı olan inanç eksikliğini ifade etmektedir. Zira Yaratılış episodu 18:13-15'te olduğu gibi; “Rab İbrahim 'e sordu: 'Sarah niçin, 'bu yaştan sonra gerçekten çocuk sahibi mi olacağım?' diyerek güldü?' Rab

\footnotetext{
13 İbrahim'in Konukseverliği Sahnesi duvar resimleri erken örneklerinden Roma Santa Maria Maggiore (5. yüzyıl) ve San Vitale Bazilika (6. yüzyıl) mozaik panolarında, Sarah'1 görmek mümkündür. Ayrıca çalışma kapsamında ele alınan el yazmaları örneklerinden 11. yüzyıla tarihlenen Vat. gr. 747 fol. 39r., 12. yüzyıla tarihlenen Vat. gr. 746 pt. 1 fol. 72v., Seraglio (Topkapı Sarayı G.İ.8) fol. 78r. ve son olarak Smyrna/İzmir A. 1 Oktateukh örneklerinde de Sarah'ın tasvirleri vardır. Özellikle el yazmaları örneklerinde tasvir edilen Sarah, bir perde arkasından bakmaktadır.
} 
için olanaksı bir şey var mı? Belirlenen vakitte, gelecek yıl bu zaman yanına döndüğümde Sarah 'ın bir oğlu olacak.' Sarah korktu, 'gülmedim' diyerek yalan söyledi. Rab, 'hayır güldün' dedi.” bu durum açikça belirtilmektedir.

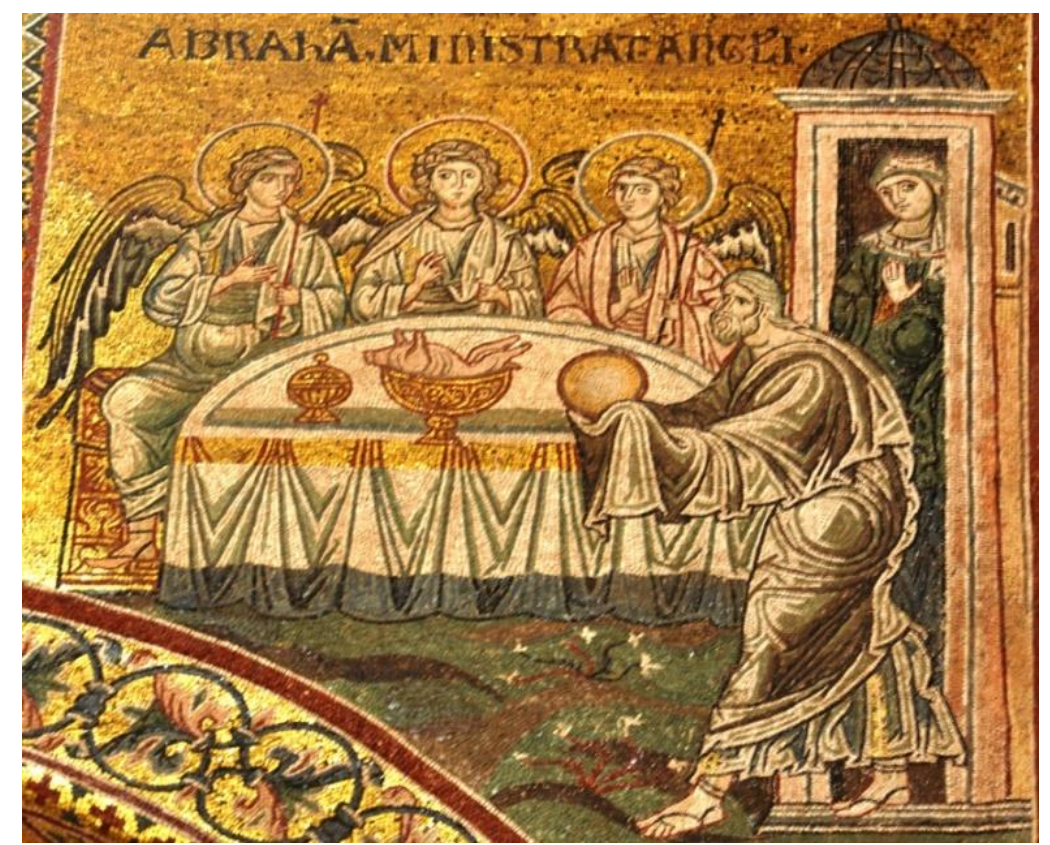

Resim 1. İbrahim'in Misafirperverliği, Monreale Katedrali

https://www.christianiconography.info/sicily/hospitalityAbrahamMonreale.html

Hacer'in resim sanatındaki tasvirleri; duvar resmi, mozaik pano, kitap resmi örneklerinde genellikle İbrahim siklusu içerisinde yer almaktadır. El yazmalarına ait resim örneklerinde, Hacer'in oğlu İsmail ile birlikte ayrıca bir siklus oluşturduğu da gözlemlenir.

Hacer ile ilgili tasvirler, en çok resimli el yazmalarında karşımıza çıkar. Bu el yazmalarından bazıları şu şekildedir. 5. ya da 6. yüzyıla tarihlenen BL Cotton MS Otho BVI referans numarası ile Cotton Genesis, Roma Vatikan Apostolik Kütüphanesinde yer alan iki el yazmas1; 11. yüzyıla tarihlenen Vat. gr. 747 ve 12. yüzyıla tarihlenen Vat. gr. 746, İstanbul Topkapı Sarayı Müzesi Kütüphanesinde muhafaza edilen Seraglio (Topkapı Sarayı G.İ.8) ve günümüze gelemeyen Smyrna/İzmir A. 1 Oktateukh $^{14}$ kitaplarında ve daha geç tarihli Bizans sonrası döneme tarihlenen 16. yüzyıl üretimi olan ve British Library'de muhafaza edilen MS 40724 No'lu Georgios Choumnos, Yaratılış ve Mısır'dan Çıkış'ın Yorumlaması isimli resimli el yazmalarında görülür.

\footnotetext{
${ }^{14}$ Bernabò (1995, s. 216); 12. yüzyıla tarihlenen İzmir A. 1 ya da Simirne/İzmir Evangelist Okulu Kütüphanesinde yer alan Simirne Oktateukh'unda da Hacer tasvirlerinin yer aldığını belirtir.
} 


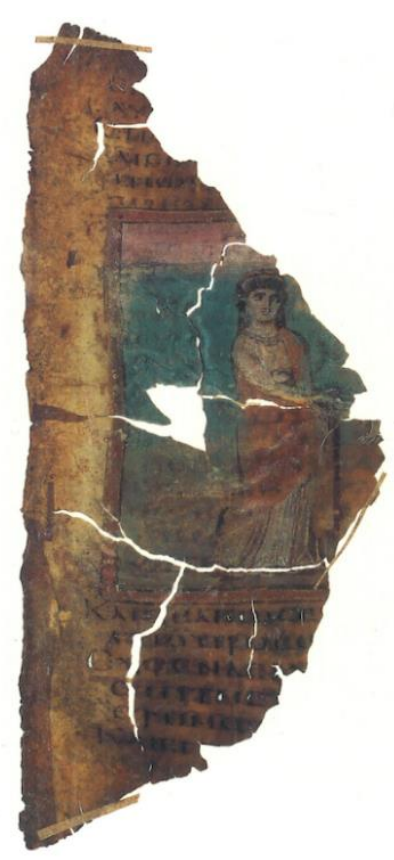

Resim 2. Hacer Tasviri, Cotton Genesis, (Weitzmann ve Kessler, 1986, s. v11, Resim 18)

Hacer'in tasvir sanatında görüldüğ̈ü ilk örneklerden birisi, 5. ya da 6. yüzyıla tarihlenen Cotton Genesis' dir ${ }^{15}$. El yazması günümüze iyi durumda gelemediği için ${ }^{16}$, kitap resimlerinde yer alan Hacer ile ilgili sahneleri algılamakta güçlük çekilmektedir ${ }^{17}$. Cotton Genesis'deki Hacer, koyu renk tenli ve saçlı tasvir edilmiştir. İki yandan örülü saçını bir diadem tamamlamaktadır. Üzerinde, açık renkli bir khiton üstüne koyu renk ve tek omuzu açıkta bırakan tunik/chlamys vardir (Resim 2).

11. yüzy1la tarihlenen Vat. gr. 747 fol. 42v.'de; Ibrahim'in, Hacer ve Ismail' $i$ Uzaklaştırması ve Hacer ve Ismail Çölde sahneleri birlikte verilmiştir. Kırmızı bir kontur ile çerçeve içine alınan sahnelerden; İbrahim 'in Hacer'i Uzaklaştırması sahnesinde İbrahim, yaşlı ve beyaz sakallıdır. Başında; altın renkli bir hale ve üzerinde de açık mavi khiton üstünde açık yeşil himation vardır. Hacer, diadem ile toplanmış kumral saçlı ve vücudu saran pembe khiton içinde ve kucağında küçük yaştaki oğlu İsmail ile tasvir edilmiştir (Resim 3, üstte).

Hacer ve İsmail Çölde/Hacer ve İsmail Beerşeba'nın Vahşi Doğasında sahnesinde, Hacer'in üzerinde aynı kıyafet ile tasvir edildiği gözlemlenir. İsmail ise Yaratılış episodu 21:20'de; “..çölde yaşadı ve okçu oldu..." ifadesi gereğince elinde bir yay ve okla tasvir edilmiştir (Resim 3, altta).

15 Cotton Genesis, Hacer tasvirlerinin en geniş ele alındığı el yazmalarından birisidir. Ancak günümüze kısmen gelebilmiştir. Hacer siklusu içerisindeki sahnelerden diğerleri; “İbrahim, Hacer’i Sarah'a Teslim Ederken, Hacer ve Melek Arasında Konuşma, İsmail'in Doğumu, Sarah, İsmail'i İshak ile Oynarken/Alay Ederken Yakalar, Sarah'ın İbrahim'den Hacer'i Kovmasını İstemesi, Meleğin Çölde Hacer'e Görünmesi ve Hacer'in Çölde Su Bulması" şeklindedir. Geniş bilgi için bkz. (Bernabò, 1995, s. 216).

${ }^{16}$ El yazması 1731 tarihinde büyük bir yangında neredeyse tamamen hasar görmüştür. Bu nedenle kitap resimlerini algılamak oldukça zordur. Geniş bilgi için bkz. (Dinçer, 2019, s. 404).

17 İçlerinde Sarah'ın, Hacer'i İbrahim'e Teslim Etmesi sahnesi en iyi durumda olabilen sahnedir. 


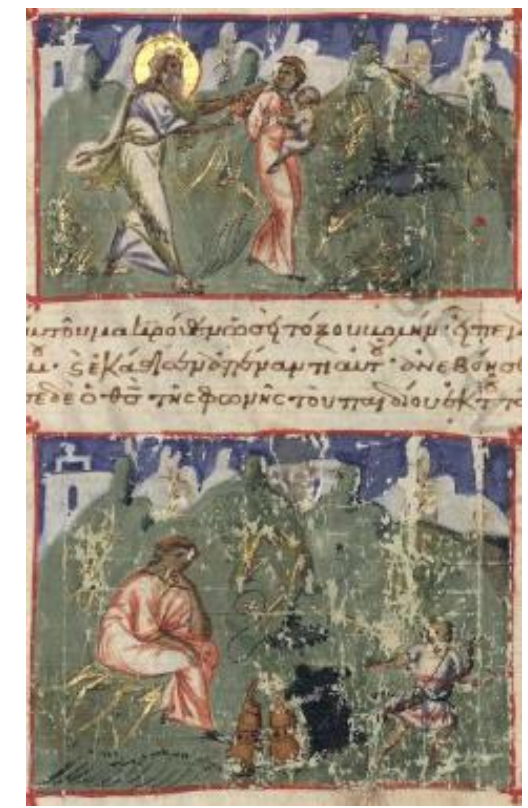

Resim 3. İbrahim'in, Hacer ve İsmail'i Uzaklaştırması (üstte), Hacer ve İsmail Çölde/Hacer ve İsmail Beerşeba'nın Vahşi Doğasında (altta), Vat. gr. 747 fol. 42v. https://digi.vatlib.it/view/MSS_Vat.gr.747

Vat. gr. 746 fol. 71r.'de; Hacer ile ilgili sahneler iç içe verilmiştir. Kırmızı bir kontur içine alınan sahneler yine kırmızı bir kontur ile ikiye bölünmüştür. Üstteki sahneler soldan sağa surasıyla; Ibrahim'in Hacer'i Sarah'a Teslim Etmesi ve Sarah'in, Hacer'i Ibrahim'e Vermesi/Teslim Etmesi şeklindedir. İbrahim mavi khiton üzerine yeşil himation, Sarah, mavi khiton üzerine bordo maphorionu/maforionu ile tasvir edilirken, Hacer sadece yeşil bir khiton ile tasvir edilmiştir (Resim 4, üstte).

Kitap resminin altında yer alan sahneler soldan sağa surasıyla; Ishak ve Ismail'in Oynarken/İsmail İshak ile Alay Ederken, İbrahim'in Hacer ve İsmail'i Uzaklaştırması, Hacer'in, Çölde Melek ile Konuşması/Meleğin Hacer'e Görünmesi ve Hacer ve İsmail Çölde/Hacer ve İsmail Beerşeba'nın Vahşi Doğasında iç içe verilmiştir (Resim 4, altta).

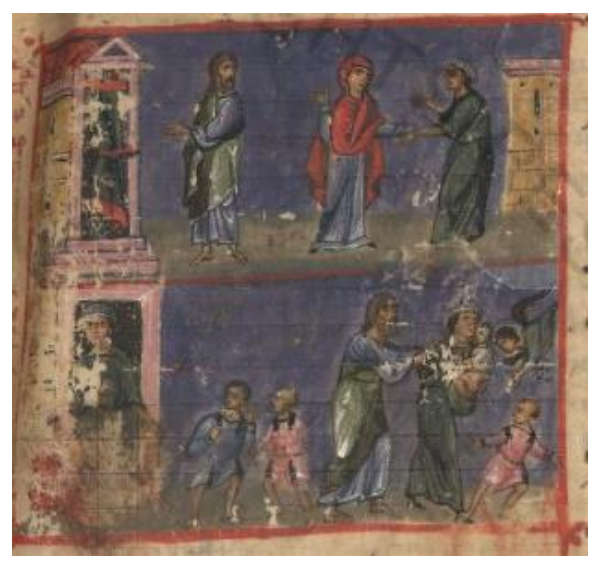

Resim 4. Hacer Tasviri, Vat. gr. 746 fol. 71r., https://digi.vatlib.it/view/MSS_Vat.gr.746.pt.1?ling=en 
12. yüzy1la tarihlenen ve günümüze gelemeyen Smyrna/İzmir A.1 Oktateukh'da yer alan Hacer tasvirleri, Vat. gr. 746'daki kitap resmi ile küçük detaylar dışında hemen hemen aynıdır (Resim 5).

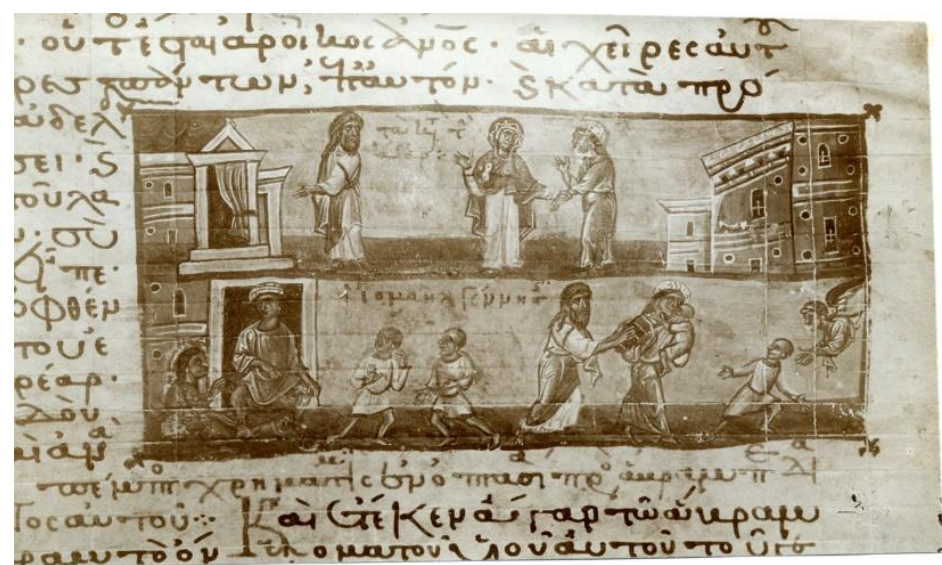

Resim 5. Hacer Tasviri, Smyrna/İzmir A. 1 Oktateukh. https://cmc.byzart.eu/items/show/127188

Topkapı Sarayı Müzesi kütüphanesinde muhafaza edilen Seraglio (Topkapı Sarayı G. İ. 8) resimli Oktateukh el yazmasında da Hacer tasvirleri vardır. Resimli el yazmasında yer alan fol. 74v.'de; Sarah'in, Hacer'i İbrahim'e Vermesi sahnesi yer alır. Kitap resmi günümüze deforme olarak gelebilmiştir. Yüzleri tamamlanmayan sahnede, ortada yer alan Sarah, Hacer'in elinden tutmuş ve İbrahim'e verirken/teslim ederken tasvir edilmiştir ${ }^{18}$ (Resim 6).

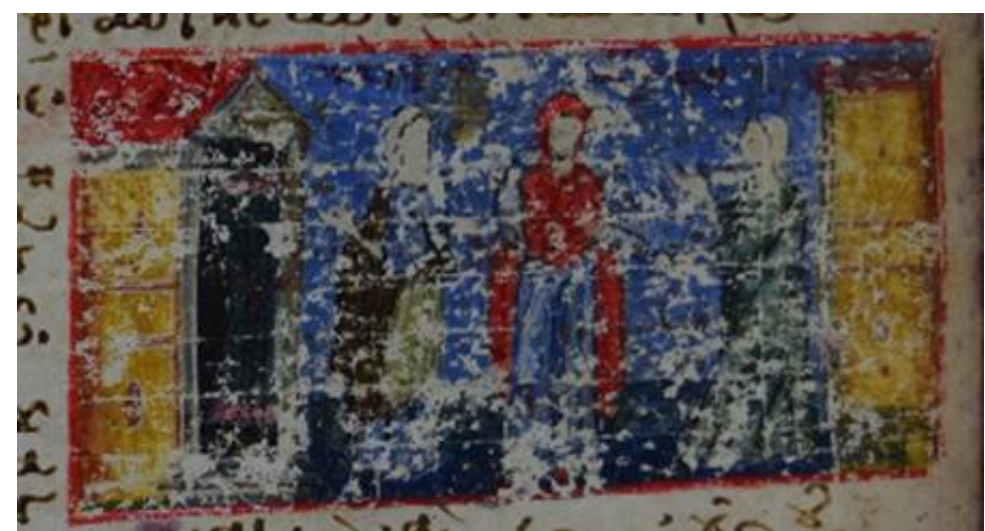

Resim 6. Sarah'ın, Hacer'i İbrahim'e Vermesi, Seraglio (Topkapı Sarayı G. İ. 8), Kat. No:64 fol. $74 \mathrm{v}$. (Kaplan, 2017, s. 135)

Resimli el yazmalarında yer alan Hacer tasviri için son örneğimiz, 16. yüzyıla tarihlenen ve British Library'de muhafaza edilen MS 40724 No'lu' ${ }^{19}$ el yazmasına ait kitap resmidir. Resimde, iki ayrı sahne vardır. İbrahim 'in, Hacer ve Ísmail 'i Uzaklaştırması sahnesinde; İbrahim

\footnotetext{
${ }^{18}$ Oktateukh'da ayrıca Hacer'in Çöle Kaçması ve Melek ile Konuşması/Meleğin Hacer'e Görünmesi sahneleri de yer alır. Geniş bilgi için bkz. (Kaplan, s. 135-137).

19 16. yüzyıla ait olan ve British Library'de muhafaza edilen Georgios Choumnos Tekvin/Genesis ve Çıklş'ın Yorumlanması isimli el yazması, Sina Azize Katarina Manastırı üretimidir.
} 
bir pınardan su doldurmaktadır ${ }^{20}$ ve biraz yiyeceği Hacer'in omuzuna yüklemiştir ${ }^{21}\left(\operatorname{Resim}^{7}\right.$, üstte). Hacer ve İsmail Çölde/Hacer ve İsmail Beerşeba'nın Vahşi Doğasında sahnesinde İbrahim, Hacer ve İsmail'in uzaklaşmalarını izlemektedir. Sahne; İbrahim'in Hacer ve İsmail'i uzaklaştırması ve Hacer ve İsmail'in çöldeki günlerini, bir sahnede birleştirmesi adına da diğer kitap resmi örneklerinden ayrılmaktadır (Resim 7, altta).

Yukarıda değerlendirilen diğer kitap resmi örnekleri ile kıyaslandığında, her iki sahnede yer alan üç karakter (İbrahim-Hacer-İsmail) beklenenin aksine açık tenlidir (Resim 7).

Bu bağlamda, kitap resminin tarihi de göz önüne alındığında, Bizans sonrası dönemde, Hacer tasvirinde üslup olarak değişim gözlemlenir. Sahnedeki üç ismin (İbrahim-Hacer-İsmail) kıyafetleri de Bizans resminin alışılmış örneklerinin aksine, Latin kitap resmi örneklerini andırmaktadır. Latin kitap resmi üslubunu, Hacer ve İsmail'in saçlarını toplama biçimlerinde de görmek mümkündür.

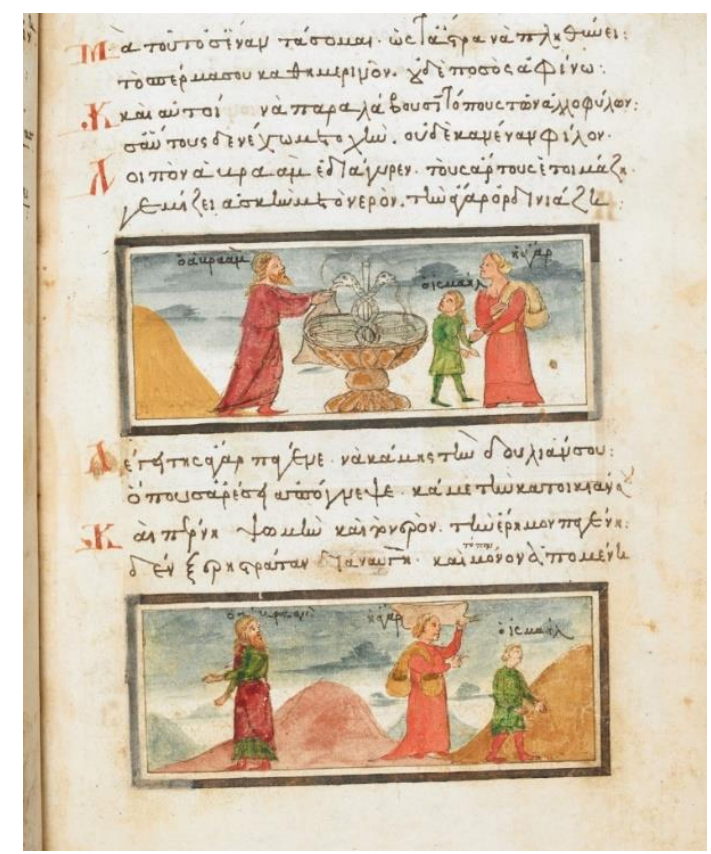

Resim 7. İbrahim, Hacer ve İsmail'i Uzaklaştırırken Sahnesi. (Üstte)

Hacer ve İsmail Çölde/Hacer ve İsmail Beerşaba'nın Vahşi Doğasında (Altta)

$$
\text { fol. 58r. (MS 40724) }
$$

http://www.ruicon.ru/arts-new/books/1x1-

dtl/grecheskaya_rukopis/i_nashel_ee_angel_gospoden_u_istochnika_vody_v_pustyne/?page_19=911\&p_

f_13_temp_id=1\&p_f_13_41=1\&ref-cat=

\footnotetext{
20 İbrahim'in tuluma su doldurduğu pınar dikkat çekicidir. Yunan mitolojisinde yer alan tanrı Hermes'in asası olan Caduceus'u andirmaktadır.

${ }^{21}$ Sahne, Kitab-1 Mukaddes Yaratılış episodu 21:14 referanslıdır. "İbrahim sabah erken kalktı, biraz yiyecek, bir tulum da su hazırlayıp Hacer'in omuzuna attı, çocuğunu da verip onu gönderdi. Hacer Beerşeba Çölü'ne gitti, orada bir süre dolaştı."
} 
Değerlendirme kapsamında ele alınan mozaik pano örneği, 13. yüzyıla tarihlenen Venedik San Marco Katedrali'nde İbrahim siklusuna ayrılan bölümde yer alır. Örneğimizde, iki sahne bir pano içerisinde verilmiştir. Soldaki sahnede İbrahim, Hacer'i Sarah'a Teslim Ederken sağdakinde ise Hacer'in, Çölde Melek ile Konuşmast/Meleğin Hacer'e Görünmesi tasvir edilmiştir. Sahnede; Hacer'in başı açık, saçları toplu ve üzerinde bir khiton vardır. Hacer'in aksine Sarah, açık renkli bir khiton üzerine, koyu renk bir maphorion/maforion içerisinde tasvir edilmiştir. Bu bağlamda Sarah, Hacer'in tasvirine göre daha vakur ve ölçülü bir kadın betimlemesi olarak karşımıza çıkar (Resim 8).

Sağdaki sahnede, Hacer bir su kenarında melek ile sohbet etmektedir. Hacer'in üzerinde, ilk sahnede yer alan kıyafetleri vardır. Meleğin başında altın rengi halesi ve üzerinde açık renkli khitonu üzerinde, açık renk chlamys vardır (Resim 8).

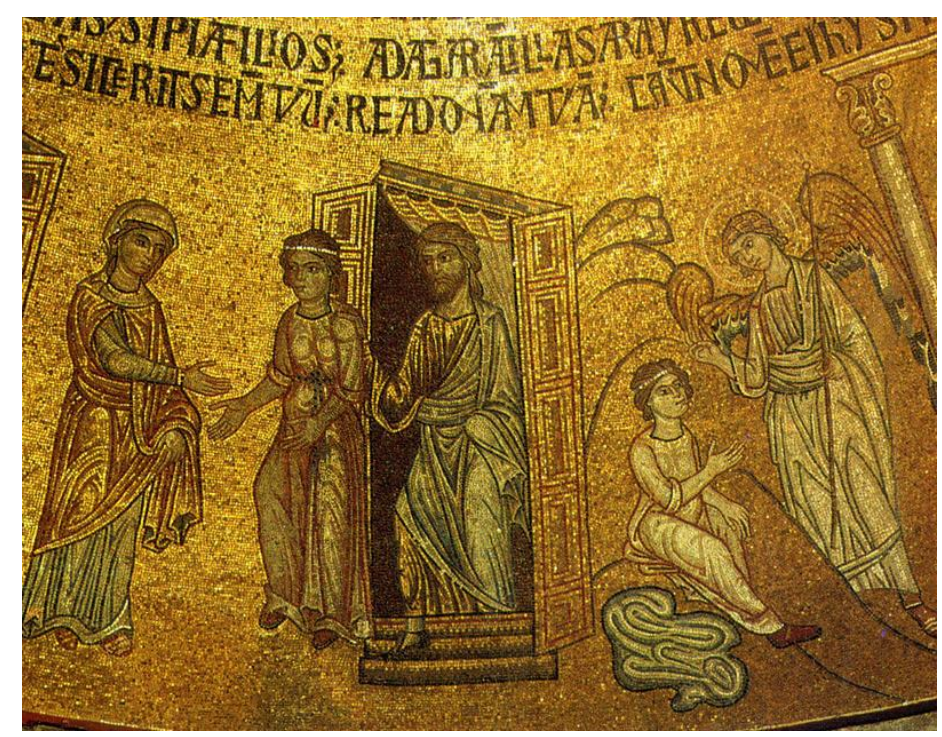

Resim 8. Venedik San Marco Katedrali. İbrahim, Hacer’i Sarah'a Teslim Ederken (solda),

Hacer'in, Çölde Melek ile Konuşmasi/Meleğin Hacer'e Görünmesi (sağda)

https://cmc.byzart.eu/items/show/76170/

\section{Sonuç}

Bu çalışmada, Bizans ve Hıristiyan resim sanatında çok sık görülmeyen Hacer tasviri ele alınmıştır.

Kitab-1 Mukaddes’te kadınlara yüklenen birçok misyon vardır. Özellikle Eski Ahit’te eril etkinin karşısında, dişil nitelikli bir güç olarak karşımıza çıkar. Bu bağlamda, Eski Ahit’te yer alan kadınlar ya iyiliğin ya da kötülüğü temsil ederler. Örneğin; Havva, İzebel ve Delila Tanrı'ya itaatsizliği ve kötülüğü temsil ederken diğer taraftan Ruth, Esther ve Miriam Tanrı'nın yanında olmayı, kadının cesaretini ve gücünü ifade etmektedir. Bunlara ek olarak, Eski Ahit’te üçüncü bir sınıflamaya gidilebilir. Bu sınıflamaya; Tanrı'ya yakarışları sonucu, Tanrı'nın bir lütuf olarak 
çocuk verdiği kadınlar eklenebilir. Bu gruba örnek verilebilecek kadınlar arasında; Hannah, Rakel ve Sarah vardir.

Bu sınıflamalar içerisinde Hacer apayrı bir karakter çizer. Hakları olmayan köle bir kadındır. İbrahim'den bir oğlu olmuş ve Sami ırkının atası olması noktasında önemli bir görev üstlenmiştir. Çocuk sahibi olduktan sonra hanımı Sarah'a karşı tavrı değişmiş ve kibirli bir karakter çizmiştir. Bu tepeden bakan özelliği onun hanımı tarafından şiddet görmesine neden olmuştur. Çöle kaçan Hacer ile melek arasındaki diyalog, Eski Ahit’te ünik bir özellik gösterir. Köle ve farklı bir etnik kimliğe ait bir kadına, soyunun çoğalacağına dair bir Tanrı vaadi söz konusudur. Diğer taraftan Hacer'in Yaratı1ış episodu 16:13'teki melek ile konuşmasındaki şu ifade önemlidir; "Beni gören Tanrl'yı gerçekten gördün mü? Diyerek kendisiyle konuşan Rab 'be El-Roi adını verdi." Hacer' in “Beni gören Tanrl'yı gerçekten gördün mü?” ifadesinde, Tanrı'ya karşı bir güven, itaat ve beklenti vardır. Bu yönüyle Hacer, Yahudi olmayan ama Tanrı'ya itaat eden bir kadın portresi çizer. Hacer; hem kibirli, küçük bir fırsatı lehine çevirmeye çalışan, baskıya dayanamayan, hanımına itaat etmeyen bir kadın kimliği sergilemesinin yanı sıra, hem de kendisine bir Tanrı lütfu olarak erkek evlat bağışlanan ve Tanrı’ya itaat ve bağlılık sergileyen bir kadın olarak karşımıza çıkar.

Hacer'in sergilemiş olduğu bu karakteristik özelliklerden dolayı onu ne iyi ne de kötü bir kadın olarak değil, nötr bir karakter olarak algılamak mümkündür.

Tasvir sanatında, Hacer'in yer aldığı örnekler incelendiğinde, Hacer'i gördüğümüz sahneler genelde; Ibrahim, Hacer'i Sarah'a Teslim Ederken 22 , Ibrahim 'in, Hacer ve İsmail'i Uzaklaştırması, Hacer'in, Çölde Melek ile Konuşması/Meleğin Hacer'e Görünmesi ve Hacer ve Ísmail Çölde/Hacer ve İsmail Beerşeba'nın Vahşi Doğasında şeklindedir. Sahnelerin ikonografisi genelde, Hacer'in hanımı Sarah'a karşı itaatsizliği, kovulması ve oğlu İsmail'in, İshak'a ortak olarak istenmemesi üzerine uzaklaştırılması üzerine kuruludur. Sahneler içerisinde; Hacer'in, Çölde Melek ile Konuşması/Meleğin Hacer'e Görünmesi sahnesinin, diğerlerinden bir fark1 vardır. Diğer sahneler, daha ziyade Hacer'in "öteki, istenmeyen, kovulan kadın” olması üzerine kurulu iken, melek ile konuşması sahnesinde, Tanrı'nın ona melek aracılı̆̆ı ile vaadi söz konusudur. Bu yönüyle sahnede Hacer, Tanrı'nın şefkatini esirgemediği bir kadın figürü olarak da yerini alır.

Bizans resim sanatında Hacer, sıklıkla tasvir edilen bir kadın portresi olarak karşımıza çıkmaz. Tasvirlerinde genelde; koyu tenli ve kıyafetlerinin tasviri ile bir cariye karakteri çizer. Yukarıda değerlendirme kapsamında ele alınan resim örneklerinde, Sarah ve Hacer'in sosyal statülerinin farklılığı en çok kıyafetleri ile verilmeye çalışılmıştır. Sarah, soylu kadınların önemli

${ }^{22}$ Yaratılış episodu 21:9-10'da da belirtildiği üzere; Sarah, İsmail'in dalga geçtiğini görmesi üzerine, Hacer ve İsmail'in kovulmalarını ister. Eski Ahit kaynaklı bu olay, Bizans resim sanatında, "Sarah, Hacer'i İbrahim'e Teslim Ederken" olarak yerini alır. 
bir göstergesi olan maphorion/maforion ile tasvir edilirken, Hacer başı açık ve üzerinde, tunik olmadan sadece bir khiton ile tasvir edilmiştir.

Sonuç olarak, Bizans resim sanatında Hacer'in tasvirleri daha çok Sarah tasvirleri üzerinden değerlendirilir. Bu bağlamda Hacer tasvirlerde, Kitab-1 Mukaddes referanslı olarak öteki kadın figürü olarak karşımıza çıkar.

\section{Kaynakça}

Adamo D., T. \& Erivwierho, F., E. (2005). The African wife of Abraham (Gn 16:1-16; 21:8-21), OTE 18 (3), 455-471.

Angel, H. (2013). Sarah's Treatment, of Hagar (Genesis 16): Morals, Messages, and Mesopotamia. Jewish Bible Quarterly 41:4(164). 211-218.

Bernabò, M. (1995). Agar e Ismaele: varianti non conosciute di Genesi 16 e 21 nella illustrazione bizantina dei Settanta. Orientalia Christina Periodica. 61(1). 216-227.

Dinçer, S., P. (2019). Erken Bizans Dönemi Resimli Dini El Yazmaları, Art-Sanat, 12, 385-420.

Drey, P., R. (2002). The Role of Hagar in Genesis 16. Andrews University Seminary Studies. 40(2). 179-195.

Faleni, M., W. (2008). Hagar: Case Study of Abuse of Women. MA. Dissertation. Cape Town: University of the Western Cape.

Gaiser, F., J. (2014). Sarah, Hagar, Abraham - Hannah, Peninnah, Elkanah: Case Studies in Conflict, Word \& World, 34(3). 273-284.

Ginzberg, L. (1998). The Legends of the Jews, trans. H. Szold (Philadelphia: Jewish Publication Society of America, 1909).

Grabar, A. (1953). The Great Centuries of Painting. Byzantine Painting. A. Skira (ed.). S. Gilbert (trans.). Cleveland: The World Publishing Company.

Gregg, C., R. (2015). Shared Stories, Rival Tellings: Early Encounters of Jews, Christians, and $\begin{array}{llll}\text { Muslims. } & \text { Oxford }\end{array}$ DOI:10.1093/acprof:oso/9780190231491.003.0007

Grimes, J. (2004). Reinterpreting Hagar's Story. lectio difficilior 1. 1-12. ISSN 1661-3317 http://www.lectio.unibe.ch

Gürgen, İ. (2018). Hammurabi Kanunları'nda ve Tevrat'ta Kadınla İlgili Hükümlerin Değerlendirilmesi, MCBÜ Sosyal Bilimler Dergisi, 6(4), 333-348.

Hawk, L., D. (2011). Cast Out and Cast Off: Hagar, Leah, and the God Who Sees. Priscilla Papers, 25(1). 9-13.

Kaplan, N. (2017). Bizans Dönemi Resimli Oktateukh El Yazmasl: Seraglio (Topkapı Sarayı G.I. .). Yayınlanmamış Doktora Tezi. Anadolu Üniversitesi. Eskişehir. 
Kitab-1 Mukaddes (2012). Kitab-ı Mukaddes Eski ve Yeni Ahit. İstanbul: Kitab-1 Mukaddes Şirketi.

Okoye, J., C. (2007). Sarah and Hagar: Genesis 16 and 21, Journal for the Study of the Old Testament, 32 (2), 163-175.

Pinker, A. (2009). The Expulsion of Hagar and Ishmael (Gen 21:9-21), Women in Judaism: A Multidisciplinary Journal, 6 (1), 1-24.

Rix, C., M. (2015). Trauma and Narrative Wreckage in the Biblical Story of Hagar. Cultural and Religious Studies 3(3). 167-176 doi: 10.17265/2328-2177/2015.03.005.

Spitzer, T. (1998). “Where do You Come from, and Where Are You Going?”: Hagar and Sarah Encounter God. Atlas Serials. 8-18.

Teubal, S., J. (1997). Ancient Sisterhood. The Lost Tradition of Hagar and Sarah, Athens: Ohio University Press.

Weitzmann, K. and Kessler, H. (1986). The Cotton Genesis: British Library, Codex Cotton Otho B. VI. Princeton, NJ: Princeton University Press.

\section{İnternet Kaynakları}

https://avalon.law.yale.edu/ancient/hamframe.asp

https://cmc.byzart.eu/items/show/127188

https://cmc.byzart.eu/items/show/76170/

https://digi.vatlib.it/view/MSS_Vat.gr.746.pt.1?ling=en

https://incil.info/kitap/gen/21

https://www.turkcebilgi.com/hacer

https://www.christianiconography.info/sicily/hospitalityAbrahamMonreale.html

http://www.ruicon.ru/arts-new/books/1x1-

dt1/grecheskaya_rukopis/i_nashel_ee_angel_gospoden_u_istochnika_vody_v_pustyne/?page_19

=911\&p_f_13_temp_id=1\&p_f_13_41=1\&ref-cat= 